\title{
The social impacts of a special event on the host city: a conceptual framework and a case study of the Cincinnati Flying Pig Marathon
}

\author{
Julie Cencula Olberding* \\ Northern Kentucky University, \\ 424 Founders Hall, \\ Highland Heights, KY 41099, USA \\ E-mail: olberdingj@nku.edu \\ *Corresponding author
}

\section{Douglas J. Olberding}

Xavier University,

Joseph Building, 3rd Floor,

Cincinnati, OH 45207, USA

E-mail: olberdin@xavier.edu

\begin{abstract}
This article provides a conceptual framework to study the potential impacts of a special event on the host city's social assets. This framework is more encompassing than traditional studies of social impact, which tend to focus only on city image; it includes local pride, social networks, and support of social causes. It then presents a case study of the Cincinnati Flying Pig Marathon and its social impacts on the host city, using unique data from surveys of participants (2002 and 2008) and volunteers (2012). The analysis finds some evidence that this event has had positive effects on Cincinnati's social assets.
\end{abstract}

Keywords: special events; host city; social impacts; city image; local pride; social networks; social causes; participants; volunteers.

Reference to this paper should be made as follows: Olberding, J.C. and Olberding, D.J. (2014) 'The social impacts of a special event on the host city: a conceptual framework and a case study of the Cincinnati Flying Pig Marathon', Int. J. Hospitality and Event Management, Vol. 1, No. 1, pp.44-61.

Biographical notes: Julie Cencula Olberding is the Director of and Associate Professor of the Master of Public Administration (MPA) programme at Northern Kentucky University. Her research has focused on non-profit organisations and management, philanthropy and volunteerism, and economic and community development. It has been published in Public Administration Review, Economic Development Quarterly, International Journal of Public Administration, International Studies Perspective, Journal of Public Affairs Education and Innovative Higher Education. She obtained her MPA and PhD from the Martin School of Public Policy and Administration at the University of Kentucky and her Bachelor's degree from the EW Scripps School of Journalism at Ohio University. 
Douglas J. Olberding is the Chair of and Associate Professor at the Department of Sport Studies, Xavier University. His research has focused on the economic impact of sport events, branding of sport events, and strategic planning and management of sport organisations. His articles have been published in the International Journal of Sport Management, International Journal of Sport Finance, Sport Marketing Quarterly, and International Studies Perspective. He obtained his doctoral degree in Sport Management from the University of Kentucky, a Master's degree in Political Science from Ohio University, and a Bachelor's degree in Political Science from Xavier University.

\section{Introduction}

Foot races, festivals and other special events are phenomena that have been around almost since the creation of the cities that host them. But interest in and studies of how these events impact host cities have come to the surface in relatively recent years. In particular, a number of studies have analysed the economic impact of marathons, which are 26.2-mile foot races, on the host cities. Some of these studies have found that recent major marathons have had a huge economic impact on the host city, such as $\$ 138$ million for the 2012 Boston Marathon (Johnston, 2012) and \$340 million for the 2011 New York City Marathon (Belson, 2011). However, most of these analyses have not been subject to scholarly review, and critics have asserted that they overestimate economic impacts (e.g., Porter, 1999; Crompton, 1995). Only one economic impact analysis of a marathon seems to have survived the peer review process and been published in an academic journal (Cobb and Olberding, 2007). The authors develop a method to correctly account for the impact of local marathon participants, which results in a more conservative measure of economic impact than previous analyses. Applying this method, they find that the economic impact of the Cincinnati Flying Pig Marathon is about $\$ 9$ million to $\$ 10$ million per year (Cobb and Olberding, 2007, 2008, 2012).

A few scholarly articles have looked beyond the economic impacts of special events to the social impacts on the cities or communities that host them. These studies tend to focus on one social asset: city image. This article develops a more comprehensive conceptual framework of a community's social assets - including not only city image but also local pride, social networks, and support of social causes - and the potential impacts of a special event on them. In doing so, it discusses ways in which event organisers and/or local governments may be able to leverage such an event in order to have intentional and positive impacts on these social assets.

This article begins with a review of relevant literature. Next, it develops a conceptual framework for studying a city's image and other social assets and then discusses how a special event can impact these social assets. Finally, it presents a case study of the Cincinnati Flying Pig Marathon, including results from two participant surveys (2002 and 2008) and one volunteer survey (2012).

\section{Literature review}

Scholars and observers have recognised city image as a key asset that contributes to the community's ability to attract businesses and individuals (e.g., Schmid, 2005; Bradley 
et al., 2002). "At the dawn of the Global Century, business leaders say, the international image of a city and its region has never been more crucial for recruiting new business talent and opportunity" (Schmid, 2005). But what is city image? Lee (2006, p.367) defines it as "the subjective view or perception of a city". Morgan and Pritchard (1998) describe image as the 'currency of culture' in that it reflects and reinforces particular shared meanings, beliefs and values about the city. The concept of city image is related to the concept of brand. A brand is a name and/or symbol that has the dual purpose of identifying a good or service of a particular firm and differentiating them from those of other competing firms (Aaker, 1991). Generally speaking, a brand is designed to positively influence the image of a good or service - or the shared perceptions or views among consumers and potential consumers. Therefore, a city brand could be defined as the name and/or symbol that have the dual purpose of identifying the city and differentiating it from other cities in an effort to enhance its image.

Cities have initiated a number of different strategies in order to enhance their image directly or indirectly. Three of the traditional strategies to enhance city image are:

1 marketing, advertising and public relations campaigns

2 development and enhancement of physical assets

3 attraction and retention of professional sport teams.

First, cities have to enhance their image through marketing, advertising and public relations campaigns. For example, the city of Cancun, Mexico used marketing and advertising to try to change its image from one marked by "wet T-shirt competitions and cheap beer and tequila" for college students, according to an article in The Economist. Leaders of the tourism industry felt that spring-breakers 'hijacked the city's image' despite the fact that they constituted only $1 \%$ of the visitors or tourists per year (The Economist, 2005). In order to continue to attract newlyweds, eco-tourists and golfers, the city of Cancun launched a new marketing campaign that focuses on the sun, surf and golf greens. In Milwaukee, Wisconsin, business and civic leaders launched a five-year, \$12 million campaign to create a new image and market it to people around the world. Spirit of Milwaukee Inc. - a non-profit organisation consisting of primarily business leaders led the campaign. An article in The Journal Sentinel quoted Dean Amhaus, Spirit of Milwaukee president, as saying about people outside of the city, "It was not so much that they had negative perceptions of Milwaukee. They had no perceptions" (Schmid, 2005).

Secondly, cities have tried to enhance their image through the construction and enhancement of buildings and other physical assets, including convention centres, museums, and sport and concert arenas. Many postindustrial western cities are using 'high-profile' or 'flagship' projects designed "to encourage business investment from outside the locality and to upgrade the image of the city to potential investors and tourists" [Lee, (2006), p.368]. Richards and Wilson (2004, p.1931) assert that "signature buildings frequently feature in urban strategies to develop an image or 'brand' and create competitive advantage, often at great financial cost". Recent examples, they say, are the Guggenheim museum in Bilbao, Spain, and the Tate Modern gallery in London. Leaders in Newark, New Jersey, also made a big investment in physical assets with the hope that it will improve the city's image. The city paid about $\$ 210$ million for the construction of the Prudential Center, and the owners of the New Jersey Devils paid the balance of $\$ 180$ million. Newark Mayor Cory Booker called the arena 'the new face of Newark' (Townes, 2007). "Many residents of Newark, as well as city officials, hope the new Prudential 
Center will help restore the sullied image of Newark as a dangerous and crime-ravaged city with a bleak economic future.... Others believe that the new arena will give the city an economic jolt and to the residents, hope" (Townes, 2007).

Thirdly, some cities try to enhance their image is by attracting and retaining professional sport teams, particularly major-league football, baseball and basketball teams. These strategies related to sport teams can be intertwined with strategies related to physical assets, such as public financing of the construction or renovation of a facility. But there are other sport team strategies that are not linked to physical assets, such as direct cash payments to professional sport team owners. "[T]he presence of a sport team can play a role in a city's efforts to enhance its image. This can increase local pride in the community and it can be useful for attracting industry and tourists" [Sparvero and Chalip, (2007), p.13]. One empirical study found that a National Football League (NFL) team enhanced the perception of quality of life by residents of the host city (Johnson et al., 2007).

But there is some indication that cities are moving away from these more traditional strategies of image enhancement, especially those involving physical assets and professional sport teams. Richards and Wilson (2004) say that cities are disengaging to some degree from 'infrastructure-based strategies' - those that focus on architecture and physical space - because they are expensive and inflexible. In addition to direct costs, Sparvero and Chalip discuss the opportunity costs, or the forgone value or benefits of alternative strategies. "When public funds are spent to attract or retain a professional team, those funds are unavailable for education, recreation, libraries, or other projects that could benefit a larger number of residents" [Sparvero and Chalip, (2007), p.2]. Most importantly, claims of economic benefits of professional sport teams have been 'widely discredited', according to Sparvero and Chalip. For example, the Cincinnati Bengals stadium cost county taxpayers more than $\$ 350$ million to build in 2000 and about $\$ 30$ million per year to operate, which is $11 \%$ of the county's annual budget. "The Bengals had said that with a new stadium, the team's revenue would increase, allowing it to sign better players, win more games and attract more fans to the area. ... [T] he team has managed just two winning seasons in the new facility. Its attendance levels have actually dropped" (Albergotti and McWhirter, 2011).

Leaders in some cities are turning to special events as a less costly and more flexible way to enhance city image. Richards and Wilson (2004, p.1932) assert that events "have emerged as a means of improving the image of cities, adding life to city streets and giving citizens renewed pride in their home city". Hall (1992, p.14) says that "major events can have the effect of sharing an image of the host community or country, lending to its favourable perception as a potential travel destination". The value that some city leaders place on such events, he says, is apparent in their fierce competition to host some of them, such as the Olympic Games and the World Expo.

Studies of the impact of an event on city image have typically been done in the context of large-scale 'mega-events', such as the Olympics Games and the World Cup Final (Higham, 1999). But scholars are beginning to look at the impact of festivals and other 'non-mega' events on city image. Higham asserts that recurring small-scale events have the potential to provide the community with more net benefits than one-time mega-events or 'hallmark' events because they require fewer public resources and may be less prone to crowding and congestion. For example, Puczko and Ratz (2001) studied the Budapest Spring Festival in Hungary found that overall festival participants had a more positive image of the city of Budapest than non-festival-goers. Also, Richards and 
Wilson (2004) studied the Cultural Capital of Europe (CCE) event in 2001 and they concluded that Rotterdam's image was enhanced among both local residents and non-residents (i.e., visitors or tourists).

\section{Conceptual framework: the social impacts of a special event on the host city}

The conceptual framework of this article goes beyond looking at city image as the only social asset or resource, which has been the approach of most research to this point. It extends the perspective to recognise other social assets or resources of a city, using relevant work by Sparvero and Chalip (2007) as a theoretical foundation. These authors examined various impacts - economic and non-economic (i.e., social) - of professional sport teams on the cities in which they are located. In doing so, they theorise that city leaders can reap greater benefits if they leverage their professional sport teams rather than simply host them. In other words, city leaders should actively and strategically integrate a professional sport team into their economic development plans and neighbourhood redevelopment plans, not just passively wait for a team to produce economic and social benefits. Their conceptual framework identifies three categories of potential benefits that a sport team and arena can bring to the host city:

1 Economic benefits that include:

a new skilled and unskilled jobs, possibly introducing first-timers to employment

b tax base enhancement (income, sales and property tax)

c redevelopment of the neighbourhoods around the venue.

2 Place marketing benefits that consist of:

a enhancing the city image or brand by raising awareness and creating associations with desired characteristics

b increasing local residents' pride in the city and attracting them to the venue and surrounding businesses

c attracting businesses and workers to the city

d increasing the number of visitors or tourists, lengthening their stay and increasing their spending.

3 Social welfare benefits that include:

a building community and strengthening social networks

b supporting of a social cause or causes.

Since this article examines the impact of a special event on the social assets of a city, it incorporates relevant concepts from two categories of potential benefits identified by Sparvero and Chalip: place marketing (\#2 above) and social welfare (\#3 above). Specifically, it uses two of the four elements in place marketing category that are non-economic - or social - in nature and all of the elements in social welfare category. The non-economic place marketing elements are:

a enhancing the city image or brand

b increasing local residents' pride in the city and attracting them to the venue and surrounding businesses. 
The conceptual framework is shown in Figure 1 and discussed.

Figure 1 Potential social impacts of special events

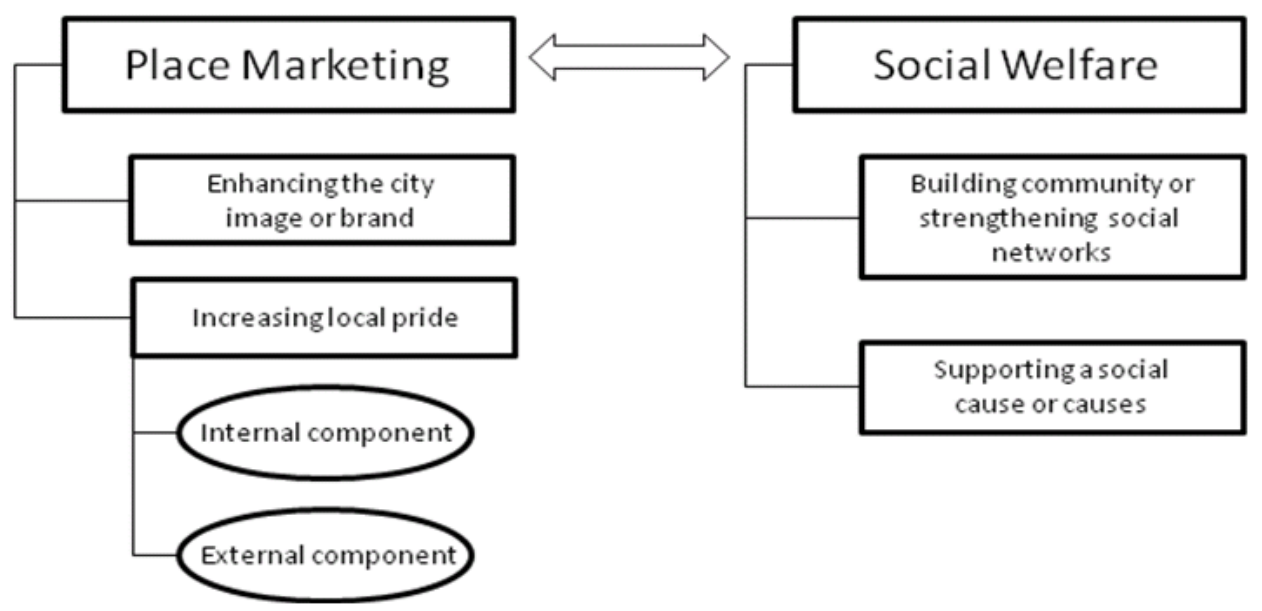

\subsection{Enhancing city image}

As discussed earlier, city image has been defined as shared perceptions or views of a city (Lee, 2006; Morgan and Pritchard, 1998), and city brand has been defined as the name and/or symbol that identifies a particular city and distinguishes it from other cities (Aaker, 1991). This article asserts that event organisers and/or local governments can leverage a special event - especially a recurring special event - in a way that results in the city's brand capturing desired or positive associations from the event's brand, based on Sparvero and Chalip's (2007) work. If the event attracts positive attention in newspapers and on television news programmes in the region, for example, then this may result in enhancement of the city's brand. One of the fundamental requirements of this leveraging opportunity is that the event must be associated with the host city name (Sparvero and Chalip, 2007). Examples of special events that are tied to a city are: the Boston Marathon, the New York City Marathon and the New Orleans Jazz Festival. Often times, though, the potential benefits of branding are lost when the event is not paired with a place or it is tied to a place that is very broad and diffuse. Examples of events that are not directly associated with a city include: the Rock and Roll Marathon (in San Diego, Seattle, and a number of other cities), the Sawdust Art Festival (in Laguna Beach, California), and the West Beach Music and Arts Festival (in Santa Barbara, California).

\subsection{Increasing local pride}

A sport team - especially if leveraged properly - can have two benefits related to local residents: enhancing their pride in the city and attracting them to the venue and surrounding businesses (Sparvero and Chalip, 2007). An extension of this idea is that a special event has the potential to foster residents' pride in their city or community - that is, their satisfaction and esteem related to their city or community. The boost in 
community pride following an event has been referred to as the 'halo effect' (Hall, 1992) and the 'feel-good effect' (Allen et al., 2002). Eckstein and Delaney (2002) say that community pride has two components:

1 an internal component, which refers to residents' own perception of their community

2 an external component, which refers to residents' belief of how outsiders perceive their community.

The second potential benefit of a special event is it can attract locals to participate in the event and patron businesses near the event. Getting local residents to participate in an event is important because they may be more likely than non-local residents - i.e., tourists or visitors - to be repeat participants (Sparvero and Chalip, 2007).

\subsection{Strengthening social networks}

A sport team - again, especially if leveraged properly - can build community and strengthen social networks through the interaction that takes place during games, at pre- and post-game parties, and through fan groups (Sparvero and Chalip, 2007). Likewise, a special event brings together participants, volunteers and others for a unified purpose. Therefore, it creates opportunities for strengthening social networks - i.e., interaction and communication - and enhancing norms of solidarity - i.e., "we're all in this together".

\subsection{Supporting social causes}

Another way that a sport team can impact a city or community is through involvement by the team and its members in supporting a social cause or causes (Sparvero and Chalip, 2007). Normally, the team partners with a non-profit organisation or charity, "lending its celebrity status, spokespersons, and events to the cause" [Sparvero and Chalip, (2007), p.22]. Potential benefits for the non-profit organisation are increased awareness and resources generated by the team, while the potential benefits for the team are favourable press and possibly enhancement of its image (Sparvero and Chalip, 2007). These authors suggest that the sport team and non-profit organisation work together on their public communications campaign in order to leverage the positive results for the team and the non-profit. In a similar way, a special event can help to support a social cause or causes. Some special events are organised with the intent of raising funds for a particular cause. For example, the March for Babies formerly known as WalkAmerica - is an event that takes place in about 900 cities in recent years and has raised \$2 billion for March of Dimes since 1970 (Why we walk, 2012). Other events are organised for a primary reason not based on addressing social problems - e.g., a marathon running event - but they provide opportunities for participants to raise funds for social causes or help them in some other manner. For example, more than 45,000 people ran or walked the Chicago Marathon in 2012. Of these, about 10,000 'charity runners' raised millions of dollars for more than 160 local, national and global causes, including the American Cancer Society, the American Red Cross, and the Leukemia and Lymphoma Society (Charity program, 2012). 


\section{A case study: the Cincinnati Flying Pig Marathon}

This article begins to apply this conceptual framework to the 'real world' by examining the impact of the Cincinnati Flying Pig Marathon on the host city's image and other social assets. It begins with some background information on the city of Cincinnati, USA, and the Cincinnati Flying Pig Marathon. Then it discusses the research design for this study including the various measures used to assess the social impacts of a special event on the host city.

\subsection{Background}

The city of Cincinnati is located in the southwest corner of the state of Ohio, along the northern banks of the Ohio River. Founded in 1788, Cincinnati became home to a large number of Germans who immigrated during the early 1800 s and beyond. Relevant to this case study is the fact that during the mid-1800s Cincinnati became the pork-processing centre of the USA. "Because of Cincinnati's association with meatpacking, the city became known as the 'Porkopolis' of the United States" (Cincinnati, Ohio, 2009). Also, relevant to this case study is a neighbourhood called Over-the-Rhine, or OTR for short. In the early 1800s, German immigrants gave it this name because the Miami and Erie Canal resembled the Rhine River in their home country. OTR has been listed in the National Register of Historic Places and the National Trust for Historic Preservation's 'Most Endangered Historic Places in America' because it has "the nation's largest contiguous collection of Nineteenth Century Italianate Architecture" (Historic preservation, n.d.). During the mid-1900s, OTR became one of the poorest neighbourhoods in Cincinnati; however, in the 1980s and 1990s, it was experiencing some gentrification and redevelopment, including restaurants, bars, unique retail shops and other small businesses.

On another front, in the 1990s, a group of runners in Cincinnati began discussing the possibility of organising a major marathon in the city. These event organisers wanted to position the race as fun rather than competitive in order to generate interest outside the traditional running community. "During brainstorming sessions, many names were suggested that had some connection to the unique qualities of Cincinnati, such as the 'River City Marathon' or the 'Seven Hills Marathon.' ... When someone in the group mentioned 'flying pigs', everyone laughed, and the organizers knew they were on to something" [Olberding and Jisha, (2005), p.194]. The 'Flying Pig' title has historical and cultural meaning for Cincinnati because, as mentioned earlier, the city had been known as 'Porkopolis'. In addition, this title has meaning for a marathon event because people faced with a seemingly impossible goal - like running 26.2 miles - sometimes use the expression "I'll do it when pigs fly".

Flying Pig organisers created a non-profit organisation called Cincinnati Marathon Inc. to manage the marathon. The first marathon was launched in 1999 with a strong branding and marketing campaign (Olberding and Jisha, 2005). At the time, the course started in downtown Cincinnati and took runners into the historic cities of Newport and Covington in Northern Kentucky - across the Ohio River - and through some neighbourhoods in Cincinnati and suburbs; however, it did not go through OTR.

In April 2001, the city of Cincinnati faced a serious crisis. Civil unrest, or riots, occurred in the city for two days after a white Cincinnati police officer shot and killed a 19-year-old black man. The activity was concentrated in OTR, and the local and national 
media provided stories and images of burning and looting. The immediate damage to buildings and other property was estimated at $\$ 3.6$ million. Also, a coalition of organisations called for a boycott of all businesses in downtown Cincinnati. A number of celebrities cancelled speaking engagements and concerts, including Bill Cosby, Whoopi Goldberg and Wynton Marsalis. In the first year of the boycott, the loss in convention and entertainment revenue was estimated at more than $\$ 10$ million.

For the Cincinnati Flying Pig Marathon in 2002, event organisers had time to consider the course in light of the riots and the negative media coverage of the city. They decided to re-route the course to go through OTR so that participants would experience the neighbourhood first-hand and see its architecture and people as a way to counter the negative news stories, videos and photos about the riots. With hindsight, it appears that Flying Pig organisers tried to leverage the event so that it would have a positive impact on participants' perceptions of the city of Cincinnati - that is, its image - as well as positive impacts on other social assets of the city (Sparvero and Chalip, 2007).

Over the years, the Flying Pig has grown into a weekend-long event with the addition of new events including a 10-kilometer race in 2003, a 5-kilometer race in 2004 and a half-marathon in 2006. The total number of participants increased from 6,000 in the inaugural year of 1999 to more than 30,000 participants in recent years. About half of participants come from inside of the Greater Cincinnati metropolitan area - i.e., local participants - and the other half come from outside of it - non-local or visiting participants.

\subsection{Research design}

The purpose of this case study is to begin to assess the impacts of a special event on the host city's social assets, including city image, local pride, social networks and support of social causes. Measuring these 'soft' social impacts of a special event - primarily through participants' perceptions and opinions - is more challenging than measuring the 'hard' economic impacts, such as participants' spending on hotel rooms, food and entertainment. In order to attempt to measure social impacts, through participants' perceptions and opinions, this study utilises a unique set of data coming from two surveys of Flying Pig participants (i.e., runners and walkers) conducted in 2002 and 2008 and a third survey of volunteers conducted in 2012.

The Flying Pig organisers have administered the participant survey since the first year of the event in 1999. Originally, the survey was designed to obtain feedback from runners and walkers on their experiences to use for the planning and organising of the event in the future, and it was in paper-and-pencil format. Beginning in 2003, Burke Inc. - a marketing research company with expertise in research design, execution and analysis began conducting the participant survey via the internet. Also, organisers have added items designed to estimate the economic impacts of the event on the city of Cincinnati.

In 2012, the authors of this article administered a survey of Flying Pig volunteers, which was the first time for a survey of this population. Some items were pulled from the 2002 and 2008 Flying Pig participant survey. The survey instrument also included a few items based on the development of the conceptual framework regarding the potential impacts of a special event on a host city's social assets. (In addition, this survey instrument included a number of items related to volunteer motivation and satisfaction. The results are being used in a different study specifically focusing on these topics.) The 
volunteer survey was administered online using SurveyMonkey, based on the seminal work on survey design and implementation by Dillman et al. (2008; Dillman, 2000). The Flying Pig volunteer coordinator sent a series of three messages to potential respondents, including a pre-notification, a notification and a post-notification (i.e., reminder or follow-up).

\subsection{Measures of social impacts}

This section discusses the various measures of social impacts in greater detail, including city image, local pride, social networks and support of social causes.

City image: The earliest attempt to measure the Flying Pig's impact on city image was in 2002, which was the year that the event organisers re-routed the event through OTR. A few simple items about city image were added to the survey of local participants. Specifically, the survey instrument included a question that asked local participants the following: "Did your participation in the marathon change your perceptions about downtown Cincinnati?" The survey instrument gave local respondents the opportunity to mark 'yes' or 'no' and also to write a narrative response. A total of 280 local participants responded to this survey.

In 2008, the authors worked with Burke Inc. to add two items about city image to the web-based survey not only for local participants but also for non-local participants in either the marathon (26.2 miles) or the half-marathon (13.1 miles). Each item was based on an 11-point Likert scale with 1 being 'extremely negative impact', 6 being 'no impact' and 11 being 'extremely positive impact'. (The items used 11-point Likert scales for consistency, as Burke used this format for other items on the participant survey). They were:

1 the degree to which the Flying Pig impacted your perception of downtown Cincinnati

2 the degree to which the Flying Pig impacted your likelihood to spend time in downtown Cincinnati in the future - e.g., to eat at a restaurant, attend a sporting event, visit a museum, etc.

More than 500 participants in the 2008 Flying Pig marathon or half-marathon responded to these items about city image.

Again, in 2012, the authors conducted a survey of Flying Pig volunteers. In terms of city image, the instrument included the same two items on city image that were on the 2008 participant survey - i.e., the Flying Pig's impact on their perception of Cincinnati and the likelihood they would spend time in Cincinnati. This instrument included one additional item: the degree to which the Flying Pig impacted the overall image of Cincinnati. In the end, more than 1,000 volunteers responded to this survey.

Local pride: In 2008, the authors requested that Burke researchers add two items designed to measure local pride, based Eckstein and Delaney's (2002) assertion that local pride has an internal component and an external component. The following two items were on an 11-point scale with 1 being 'extremely negative impact', 6 being 'no impact' and 11 being 'extremely positive impact': 
1 the degree to which the Flying Pig impacted your sense of pride in being a resident of Cincinnati

2 the degree to which the Flying Pig impacted visiting participants' perceptions of downtown Cincinnati.

(Again, the items used 11-point Likert scales in order to be consistent with other items on the participant survey). In addition, the 2012 survey of Flying Pig volunteers included the same two items designed to measure local pride.

Social networks: The conceptual framework discusses that a special event has the potential to create opportunities to strengthen social networks and for enhancing norms of solidarity. This study begins to measure the impacts on social networks by accounting for the number of participants, volunteers and spectators that engage themselves in the Flying Pig event. In addition, the 2012 survey of Flying Pig volunteers included two items that were designed to provide other measures of the event's impact on social networks and social capital. The items asked respondents to assess the Flying Pig's impact on the following (again, using an 11-point scale):

1 social networks - interaction and communication - among individuals and groups

2 feelings of community and solidarity - i.e., "we're all in this together".

Support of social causes: Finally, the conceptual framework asserts that a special event has the potential impact of supporting a social cause or causes, which is generally represented by support of non-profit organisations. This study begins to measure these impacts using data from secondary sources on the number of volunteers and amount of charitable funds raised through the Cincinnati Flying Pig Marathon. For example, information on the number of volunteers and amount of money raised for local charities came from newsletters and other publications by the Flying Pig Marathon.

\section{Results}

\subsection{City image}

In response to a question to local participants on the 2002 survey, 92 of the 280 respondents (33\%) indicated that their participation in the Flying Pig event changed their perceptions of downtown Cincinnati. And 79 of the 92 respondents $(85.9 \%)$ said it had a positive impact, while only two of them $(2.2 \%)$ said it had a negative impact. The results are shown in Table 1.

Local participants who responded to the 2002 survey were provided the opportunity to write narrative responses explaining their perceptions of downtown Cincinnati. Table 2 provides some sample comments by attribute. For example, one respondent wrote: "The marathon is such a friendly, approachable event that takes place in our city center that it overrides many of the bad impressions I had had recently about Cincinnati". And another one wrote: "A little more pride in the city, and a feeling we are 'big league' in more than just pro sports". 
Table 1 Impact of the 2002 Flying Pig on local participants' perceptions of downtown Cincinnati

\begin{tabular}{lcc}
\hline & \multicolumn{2}{c}{ Local participants } \\
\cline { 2 - 3 } & Number & Percentage \\
\hline Positive & 79 & $85.9 \%$ \\
Negative & 2 & $2.2 \%$ \\
Both positive and negative & 1 & $1.1 \%$ \\
Neutral & 10 & $10.9 \%$ \\
Total & 92 & $100.0 \%$ \\
\hline
\end{tabular}

Table 2 Sample qualitative statements by local residents who participated in the 2002 Flying Pig

Lots of places to see and things to do-restaurants, shopping, etc.

I have never really had the chance to go downtown and with everything you hear on the news, I wasn't in a hurry to go. Since I had a chance to see downtown better because of the marathon, I will probably go there in the near future. I didn't realise there were so many unique shops.

I never utilised the downtown restaurants until I ran by them and found where they were. I very much like to go downtown now due to the marathon.

I am new to the area and I never knew what the downtown really had to offer. Since the Marathon we have gone to Music Hall, twice and to a restaurant.

Friendly and hospitable people - community support

The way people came together was great - and it made me realise that I could get that feeling by attending other events downtown.

Local neighbourhood people that ran the checkpoints seemed very friendly

Safe/comfortable

My friends and I stayed at a downtown hotel the night before the marathon and went out for dinner and a drink. There were several high school proms being held downtown and it was fun to people watch. Overall, downtown seemed more safe than I have thought it to be in the past.

Physical beauty

I realised how beautiful Cincinnati really is and how it is taken for granted. I visited several neighbour[hoods] that I would never have gone to if I had not ran the Flying Pig Marathon. I always thought some areas were dangerous, but I found out otherwise. ... The areas are quite nice and they are in the process of being renovated and improved.

It gave me a chance to see the improvements that had been made to the downtown area and the riverfront area.

Easy to move around and park

Ease to get around, friendliness of people.

It's a lot nicer and more accessible than I had thought.

Clean

Some areas were much cleaner than I expected.

Diverse

I am a Cincinnati resident and felt more comfortable being downtown than in the previous few months. It was nice to see a diverse crowd united for the event.

General positive comments

I was pleased that out-of-town participants thought that Cincinnati was - as I believe a much better city than they had been led to believe by national press coverage after the April 2001 riots.

A little more pride in the city, and a feeling we are 'big league' in more than just pro sports. 
For the 2008 survey, the city image items were given not only to local participants but also to non-local or visiting participants. Table 3 displays the mean responses to general questions about the impacts of the Flying Pig event on city image including:

1 participants' perception of downtown Cincinnati

2 the likelihood that they will spend time in downtown Cincinnati in the future.

A key finding is that the Flying Pig Marathon Weekend had a very positive impact on local residents' perception of downtown Cincinnati (mean of 8.53 on an 11-point scale). This event had an even more positive impact on non-local participants (mean of 9.33). Further, the results indicate that the Flying Pig had a somewhat positive impact on the likelihood that local participants would spend time in downtown Cincinnati in the future (mean of 7.66) and an even stronger impact on non-local participants (mean of 8.76).

Table 3 Participants' assessment of the Flying Pig's impact on Cincinnati image (2008)

\begin{tabular}{|c|c|c|}
\hline & \multicolumn{2}{|c|}{ Means* (standard deviations) } \\
\hline & Local participants & Non-local participants \\
\hline $\begin{array}{l}\text { The Flying Pig's impact on their own } \\
\text { perceptions of downtown Cincinnati }\end{array}$ & $8.53(1.83)$ & $9.33(1.63)$ \\
\hline Number of respondents (n) & 229 & 298 \\
\hline $\begin{array}{l}\text { The Flying Pig's impact on the likelihood } \\
\text { of their spending time in downtown } \\
\text { Cincinnati in the future }\end{array}$ & $7.66(1.77)$ & $8.76(1.79)$ \\
\hline Number of respondents (n) & 229 & 297 \\
\hline
\end{tabular}

Notes: ${ }^{*} 11$-point Likert scale with 1 being 'extremely negative impact', 6 being 'no impact'.

Table 4 Volunteers' assessment of the Flying Pig's impact on Cincinnati image (2012)

\begin{tabular}{lcc}
\hline & \multicolumn{2}{c}{ Means*(standard deviations) } \\
\cline { 2 - 3 } & Local volunteers & Non-local volunteers \\
\hline $\begin{array}{l}\text { The Flying Pig's impact on their own } \\
\text { perceptions of Cincinnati }\end{array}$ & $9.02(1.46)$ & $9.04(1.40)$ \\
Number of respondents (n) & 937 & 53 \\
$\begin{array}{l}\text { The Flying Pig's impact on the likelihood of } \\
\text { their spending time in Cincinnati in the future }\end{array}$ & $8.47(1.99)$ & $8.94(1.81)$ \\
Number of respondents (n) & 955 & 53 \\
The Flying Pig's impact on the overall image of \\
Cincinnati
\end{tabular}

Notes: *11-point Likert scale with 1 being 'extremely negative impact', 6 being 'no impact' and 11 being 'extremely positive impact'.

Recall that similar items were included on the 2012 survey of volunteers and, interestingly, results are quite similar those from the 2008 survey of participants. As shown in Table 4, volunteers indicated that the Flying Pig Marathon Weekend had a very 
positive impact on their perception of Cincinnati (mean of 9.02 on an 11-point scale for local volunteers and 9.04 for non-local volunteers). The results also indicate that the Flying Pig had a positive impact on the likelihood that volunteers would spend time in Cincinnati in the future (mean of 8.47 for local volunteers and 8.94 for non-local volunteers).

The volunteer survey had one additional item related to city image, which asked respondents about the Flying Pig's impact on the overall image of Cincinnati. Similar to the participants' responses, volunteers indicated that this special event had a positive impact on city image (mean of 9.09 for local volunteers and 8.69 for non-local volunteers).

\subsection{Local pride}

In addition to items about local and non-local participants' perceptions of the city, the 2008 survey had two items for local participants regarding city pride. One item was designed to tap into the internal component of local pride (Eckstein and Delaney, 2002), which refers to residents' own perceptions of their community. As the first column of Table 5 indicates, the mean response was 9.17 (on an 11-point scale), indicating that the Flying Pig Marathon had a very positive impact on local participants' pride about Cincinnati. A second item was designed to tap into the external component of local pride (Eckstein and Delaney, 2002), which refers to residents' belief of how outsiders perceive their community. The mean response was 7.66, indicating that local residents believed that the Flying Pig Marathon had a somewhat positive impact on visitors' perceptions of Cincinnati.

Table 5 Impact of the Flying Pig Marathon on local pride

\begin{tabular}{lcc}
\hline & \multicolumn{2}{c}{ Means } \\
\cline { 2 - 3 } & $\begin{array}{c}\text { Local participants } \\
\text { (2008) }\end{array}$ & $\begin{array}{c}\text { Local volunteers } \\
(2012)\end{array}$ \\
\hline $\begin{array}{l}\text { Assessment of the Flying Pig's impact on } \\
\text { their own sense of pride about living in }\end{array}$ & $9.17(1.64)$ & $8.98(1.55)$ \\
$\begin{array}{l}\text { Greater Cincinnati (internal component) } \\
\text { Number of respondents (n) }\end{array}$ & 229 & 952 \\
$\begin{array}{l}\text { Assessment of the Flying Pig's impact on } \\
\text { visitors' perceptions Cincinnati (external } \\
\text { component) }\end{array}$ & $7.66(1.77)$ & $9.02(1.41)$ \\
Number of respondents (n) & & 940 \\
\hline
\end{tabular}

Notes: *11-point Likert scale with 1 being 'extremely negative impact', 6 being 'no impact' and 11 being 'extremely positive imapct'.

Again, similar items were included on the 2012 survey of volunteers and, again, results echo those from the 2008 survey of participants. As the second column Table 5 indicates, Flying Pig volunteers indicated that this event had a positive impact on their own sense of pride of living in Greater Cincinnati - i.e., the internal component - and on their beliefs about visitors' perceptions of the region - i.e., the external component. These means are 8.98 and 9.02 , respectively. 


\subsection{Social networks}

The Cincinnati Flying Pig Marathon engages a number of people throughout the weekend. In recent years, more than 30,000 people participated in the running/walking events: the marathon (as individuals or as members of four-person relay teams), the half-marathon, the 10-kilometer race, the 5-kilometer race and the kids' fun run. It should be noted that individuals train together for months prior to the event - usually at least once a week - either informally (i.e., with friends, neighbours, co-workers, etc.) or formally (i.e., through a training group or programme set up by a local running shop or non-profit organisation). Also, the relay teams tend to be sponsored by a corporation for which the four members work or by some other organisation for which they are members. The training prior to the race and running together on the day of the event tend to build community - i.e., enhanced interaction and communication - and a sense of solidarity i.e., "we're all in this together". This community building and social networking also occurs at other non-running events during the weekend, such as the pasta party, which takes place the night before the marathon and half-marathon.

In addition to the runners and walkers, this event involves about 4,000 volunteers who fill and distribute runners' bags, pass out water along the course and provide first-aid when needed (The squeal, 2009). Further, spectators line up along the 26.2-mile course spectators to cheer on the runners and the walkers, which creates additional community-building and social-networking opportunities, similarly to fans at a sport event (Sparvero and Chalip, 2007). In recent years, there have been an estimated 150,000 spectators along the course (The squeal, 2009).

In the 2012 survey of volunteers, an effort was made to quantitatively measure the Flying Pig's impact on social networks. Respondents indicated that the Flying Pig had a positive impact on social networks (mean of 8.40 for local volunteers and 8.21 for non-local volunteers). In addition, they indicated this event had a positive impact on feelings of community and solidarity (mean of 8.68 for local volunteers and 8.45 for non-local volunteers).

Table 6 Impact of the Flying Pig Marathon on social networks (2012)

\begin{tabular}{lcc}
\hline & \multicolumn{2}{c}{ Means* (standard deviations) } \\
\cline { 2 - 3 } & Local volunteers & Non-local volunteers \\
\hline $\begin{array}{l}\text { Assessment of the Flying Pig's impact on } \\
\text { social networks - interaction and } \\
\text { communication - among individuals and } \\
\text { groups }\end{array}$ & $8.40(1.68)$ & $8.21(1.84)$ \\
Number of respondents (n) & & 53 \\
$\begin{array}{l}\text { Assessment of the Flying Pig's impact on } \\
\text { feelings of community and solidarity - i.e., } \\
\text { "we're all in this together }\end{array}$ & $8.68(1.58)$ & $8.45(1.79)$ \\
Number of respondents $(\mathrm{n})$ & & 53 \\
\hline
\end{tabular}

\subsection{Support of social causes}

More than 100 non-profit organisations benefit from the Cincinnati Flying Pig Marathon, including national organisations like the Leukaemia and Lymphoma Society and the 
American Cancer Association as well as local organisations such as the Cincinnati Museum Center, Hospice of the Bluegrass, a few branches of the YMCA, various Boy Scout troops, and a number of elementary and high schools (Charity listing, n.d.). Some of these organisations provide volunteers to staff areas; in exchange, Cincinnati Marathon Inc. makes financial contributions to these profits. In addition, a number of non-profit organisations use the Flying Pig Marathon as an opportunity to raise funds for their organisations; 'charity runners' and 'charity walkers' select a non-profit and then get family and friends to sponsor them and donate funds to their cause. About $\$ 9$ million has been raised for charitable organisations through the Flying Pig Marathon since its inception in 1999 (Charity listing, n.d.).

\section{Conclusions}

This article builds upon emergent concepts and theories related to the relationship between a special event and the host city's social assets. In doing so, the conceptual framework takes a broader perspective of social assets by including not only city image but also local pride, social networks, and support for social causes. The conceptual framework is based on one that was developed to study the economic and social impacts of professional sport teams on host cities (Sparvero and Chalip, 2007). This framework is adapted to study the potential social impacts of special events on host cities. Further, the city image literature is used to build upon this framework by expanding the definition of city image to include external and internal components (Eckstein and Delaney, 2002). Ultimately, these theories and concepts are used to develop new measures of these social assets, which are then applied in a case study of the Cincinnati Flying Pig Marathon.

Of course, it should be noted that there are limitations to this study. First and foremost, the empirical portion of this article is a case study focusing on one special event in one host city in one country. Thus, a next logical step in this research programme would be to conduct similar studies of other events in other cities in the USA and beyond. Another limitation of this study is that it does not have a control group. The research design would be more robust with both an experimental group consisting of individuals who participated in a special event and a control group consisting of individuals who did not. Again, this may be another direction for future research, although it may be challenging to implement. In any case, additional studies of the social impacts of special events would be most informative and insightful if a similar conceptual framework and measures are used. That way, results could be more readily compared, contrasted and cumulated to better determine the degree to which findings are consistent and whether there are patterns or trends in them.

Moving from a discussion of the academic contributions and limitations, this study may help event organisers and city leaders in the 'real world' to better understand the ways that a special event can impact a community, especially its social assets. The case study finds evidence that the Cincinnati Flying Pig Marathon has enhanced city image among local and non-local participants; increased local participants' own sense of pride about the city and raised their perceptions of how visitors perceive Cincinnati; created opportunities for social interaction among more than 30,000 runners and walkers, 4,000 volunteers and 150,000 spectators; and raised nearly $\$ 9$ million for social causes. The positive impacts of this special event on the host city's social assets are noteworthy in light of the low amount of public funds necessary to support it, especially relative to more 
traditional strategies to improve city image and other social assets, such as capital projects and marketing campaigns. Specifically, the cost to the city of Cincinnati to support the Flying Pig Marathon is about $\$ 100,000$ per year, primarily for police and EMS services. In contrast, as mentioned earlier, the cost to county taxpayers to support the Cincinnati Bengals was more than $\$ 350$ million in 2000 for stadium construction and about $\$ 30$ million per year for stadium operations (Albergotti and McWhirter, 2011). The story of the Cincinnati Flying Pig Marathon may offer a lesson or, at least, a point of consideration for event organisers and city leaders in Cincinnati and beyond: The cost of - or investment in - a special event can be relatively low while the positive impacts on both social and economic assets of a city - or return on investment - can be relatively big. A related lesson from the literature (Sparvero and Chalip, 2007) is that event organisers and city leaders should approach special events strategically and collaboratively in order to leverage it and obtain the greatest possible positive impacts, or return on investment.

\section{Acknowledgements}

The authors would like to thank Burke Inc. for including items about social impacts to surveys of Flying Pig participants as well as Elizabeth Engelhardt for helping to develop the survey of Flying Pig volunteers.

\section{References}

Aaker, D.A. (1991) Managing Brand Equity, Free Press, New York.

Albergotti, R. and McWhirter, C. (2011) ‘A stadium's costly legacy throws taxpayers for a loss', The Wall Street Journal, 12 July [online] http://online.wsj.com/article/ SB10001424052748704461304576216330349497852.html (accessed 6 August 2012).

Allen, J., O'Toole, W., McDonnell, I. and Harris, R. (2002) Festival and Special Event Management, Wiley, London.

Belson, K. (2011) 'Marathon organizers highlight city's economic gain', The New York Times, 27 April [online] http://www.nytimes.com/2011/04/28/sports/28marathon.html? r=0 (accessed 6 August 2012).

Bradley, A., Hall, T. and Harrison, M. (2002) 'Selling cities: promoting new images for meetings tourism', Cities, Vol. 19, No. 1, pp.61-70.

Charity listing (n.d.) [online] http://www.flyingpigmarathon.com/sponsors_and_charities/charity_listing.shtml (accessed 17 November 2011).

Charity program (2012) [online] http://www.chicagomarathon.com/charity-community/ charity-program/ (accessed 17 November 2011).

Cincinnati, Ohio (2009) [online] http://www.ohiohistorycentral.org/entry.php?rec=681 (accessed 1 March 2009).

Cincinnati: Population Profile (2009) [online] http://www.city-data.com/us-cities/ The-Midwest/Cincinnati-Population-Profile.html (accessed 1 March 2009).

Cobb, S. and Olberding, D.J. (2007) 'The importance of import substitution in marathon economic impact analysis', International Journal of Sport Finance, Vol. 2, No. 2, pp.108-119.

Cobb, S. and Olberding, D.J. (2008) Economic Impact Analysis of the Flying Pig Marathon, Cincinnati, Ohio. 
Cobb, S. and Olberding, D.J. (2012) Economic Impact Analysis of the 2012 Flying Pig Marathon, Cincinnati, Ohio.

Crompton, J. (1995) 'Economic impact analysis of sports facilities and events: eleven sources of misapplication', Journal of Sport Management, Vol. 9, No. 1, pp.14-35.

Dillman, D.A. (2000) Mail and Internet Surveys: The Tailored Design Method, 2nd ed., John Wiley and Sons, New York.

Dillman, D.A., Smyth, J.D. and Christian, L.M. (2008) Internet, Mail, and Mixed-Mode Surveys: The Tailored Design Method, 3rd ed., John Wiley and Sons, New York.

Eckstein, R. and Delaney, K. (2002) 'New sport stadiums, community self-esteem and community collective conscience', Journal of Sport and Social Issues, Vol. 26, No. 3, pp.235-247.

Hall, C.M. (1992). Hallmark Tourist Events: Impacts, Management, and Planning, Belhaven Press, London.

Higham, J. (1999) 'Commentary - sport as an avenue of tourism development: an analysis of the positive and negative impacts of sport tourism', Current Issues in Tourism, Vol. 2, No. 1, pp.82-90.

Historic preservation (n.d.) [online] http://www.otrfoundation.org/historic_preservation.php (accessed 1 March 2009).

Johnson, B.K., Mondello, M.J. and Whitehead, J.C. (2007) 'The value of public goods generated by a National Football League team', Journal of Sport Management, Vol. 21, No. 1, pp.123-136.

Johnston, K. (2012) 'Boston Marathon to generate \$137.5 million', The Boston Globe, 12 April [online] http://www.baa.org/news-and-press/news-listing/2012/april/ boston-marathon-weekend-economic-impact.aspx (accessed 6 August 2012).

Lee, C.B. (2006) 'High profile projects and tourism policy in Birmingham, England: do they work to enhance the city's image and promote inward business investment?', Planning, Practice \& Research, Vol. 21, No. 3, pp.367-381.

Morgan, N. and Pritchard, A. (1998) Tourism, Promotion and Power: Creating Images, Creating Identities, John Wiley and Sons, Chichester.

Olberding, D.J. and Jisha, J. (2005) "The Flying Pig': building brand equity in a major urban marathon', Sport Marketing Quarterly, Vol. 14, No. 3, pp.191-196.

Porter, P. (1999) 'Mega-events as municipal investments: a critique of impact analysis', in Fizel, J., Gustafson, E. and Hadley, L. (Eds.): Sports Economics: Current Research, pp.61-73, Praeger, Westport.

Puczko, L. and Ratz, T. (2001) 'The Budapest Spring Festival: a festival for Hungarians?', in Richards, G. (Ed.): Cultural Attractions and European Tourism, CABI.

Richards, G. and Wilson, J. (2004) 'The impact of cultural events on city image: Rotterdam, Cultural Capital of Europe 2001', Urban Studies, Vol. 41, No. 10, pp.1931-1951.

Schmid, J. (2005) 'Paint it Milwaukee: city in transition seeks satisfaction with more contemporary image', Journal Sentinel, 1 October.

Sparvero, E. and Chalip, L. (2007) 'Professional teams as leverageable assets: strategic creation of community value', Sport Management Review, Vol. 10, No. 1, pp.1-30.

The Economist (2005) 'A break from spring break: a brave attempt at rebranding a rowdy resort', 12 March.

The squeal (2009) The Latest and Greatest News from the Cincinnati Flying Pig Marathon [online] $\mathrm{http}: / /$ www.flyingpigmarathon.com/news_flash/the_squeal/050109.shtml (accessed 17 November 2011).

Townes, G. (2007) 'New Prudential arena opens in Newark: will it help restore the city's image?', New York Amsterdam News, Vol. 98, No. 4.

Why we walk (2012) [online] http://www.marchforbabies.org/why.aspx (accessed 1 August 2012). 